\title{
Yeni Kültür Turizmi Destinasyonu: Olba Antik Kenti
}

Arş. Gör. Fatma ŞENGÜL,

İstanbul Gelişim Üniversitesi, Turizm Fakültesi

e-posta: fsengul@gelisim.edu.tr

\section{Öz}

Bu makalede tarihi ve kültürel değerleriyle zengin turizm potansiyeline sahip olan Mersin ili sinırlarında bulunan Olba antik kentinin kültür turizmi açısından önemi değerlendirilmektedir. Kültür kavramı; sanat, dil, tarih, din, mimari yapı, yaşam tarzı gibi etkenleri içine alan geniş bir kapsama sahiptir. Turistler kendilerine yabancı olan birçok ülke kültürünü tanıma amaciyla seyahat etmektedirler. Böylece farklı milletlere ait olan kültürel değerleri yerinde görüp, tanıma fırsatı elde ederler.

Mersin ili coğrafyanın kendisine sunduğu doğal güzelliklerin yanısıra tarihi ve kültürel dokusuyla da yüksek turizm potansiyeline sahiptir. Mersin; Türkiye'de önemli bir turizm destinasyonu olmasına rağmen, yüksek turizm hareketliliğine ve turist sayısına ulaşamamış, elde edilen turizm gelirinin Türkiye ekonomisi içerisinde payı düşük kalmıştır. Olba antik kenti kültür turizmi açısından cazip bir destinasyon alanı olmaya adaydır. Antik kentin sahip olduğu çekiciliklere karşın hak ettiği değeri ve ilgiyi görememesinin temelini tanıtım faaliyetlerindeki yetersizlikler oluşturmaktadır. Makalede sunulan önerilerle kentin cazip bir merkez olarak kültür turizmi hareketlerine fayda sağlayacağı düşünülmektedir.

Anahtar Kelimeler: Kültür Turizmi, Olba, Mersin Turizmi.

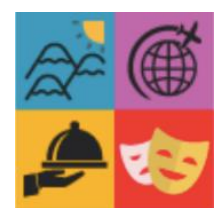

Türk Turizm Araştırmaları Dergisi Cilt. 1, Sayı.2, 2017 ss.20-28.

DOI: $10.26677 /$ tutad.2017.6

\section{Önerilen Atıf:}

Şengül, F. (2017). Yeni Kültür Turizmi Destinasyonu: Olba Antik Kenti, Türk Turizm Araştırmaları Dergisi, Cilt.1, Sayı.2, ss. 20-28. 


\title{
New Culture Tourism Destination: Olba Antique City
}

\author{
Research Assistant Fatma Şengül \\ İstanbul Gelişim University, Faculty of Tourism \\ e-mail: fsengul@gelisim.edu.tr
}

\begin{abstract}
In this article, the importance of ancient city of Olba, which is located in the Mersin province with its historical and cultural structure and high tourism potential in terms of cultural tourism, is evaluated in terms of cultural tourism. The concept of culture has a wide content including factors such as art, language, history, religion, architectural structure, life style. Tourists travel to get to know the cultures of many countries that are strangers to them. Thus they have the opportunity to see and recognize the cultural values belonging to different nations in place.

Mersin province also has high tourism potential with its historical and cultural texture in addition to natural beauties offered by the it's geography. Although Mersin is an important tourism destination in Turkey, it could not be reach high tourism mobility and the number of tourists and the share of tourism in Turkish economy remained low. The ancient city of Olba is canditate to an attractive destination for cultural tourism. Despite the attractive of the ancient city, the reason why it can not see the deserved value is in lacks of promotional activities. It is thought that the city will gain advantage from cultural tourism movements as an attractive center with the suggestions presented in article.
\end{abstract}

Keywords: Culture Tourism, Olba, Tourism of Mersin.

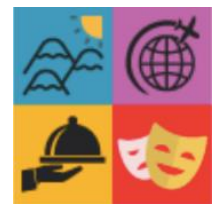

Journal of Turkish Tourism Research Vol. 1, Issue.2, 2017

pp. 20-28.

\section{Suggested Citation:}

Şengül, F. (2017). New Culture Tourism Destination: Olba Antique City, Journal of Turkish Tourism Research, Vol.1, Issue.2, pp. 20-28. 


\section{Gíriş}

Turizm, II. Dünya Savaşı'ndan sonra ekonomik bir olgu olarak önemi hızla artan bir sektördür. Özellikle yirminci yüzyılın ilk yarısında, ülke ekonomilerinin karşılaştığı ulusal ve uluslararası ekonomik sorunların çözümünde ve darboğazların aşılmasında dinamik ekonomik özellikleri ile bir çıkış noktası olmuştur (Çımat ve Bahar, 2003:1).

Anadolu toprakları birçok medeniyete ait izleri içinde barındırır. Anadolu, Asya ve Avrupa kıtalarının buluştuğu bir noktada bulunduğu ve doğal bir geçiş oluşturduğu için, tarih boyunca Asya, Avrupa ve hatta Afrika'dan gelen sayısız göç dalgalarının kavşak noktasını olmuştur. Anadolu, bu kavşakta bulunan değişik uygarlıkları sentezleyerek yeni bir biçim ve renk vermiştir (Değirmencioğlu ve Ahipaşaoğlu, 2011:3). Olba antik kenti de köklü geçmişi ve barındırdığ değerlerle Anadolu topraklarında yer alan önemli bir antik kenttir. Olba antik kentinde yürütülen kazılar sonucunda yerli ve yabancı turistin ziyaretine sunulabilecek eserlere ulaşılmıştır.

Kültür; dil, tarih, din, mimari yapı, sanat, adet, gelenek ve görenekler gibi etkenleri içine alan geniş bir kavramdır. Bu etkenlerin içerisinde mimari yapılar büyük önem taşır. Mimari kalıntılar bir ülkenin topraklarında barındırdığı medeniyetler hakkında bilgi verirken; aynı zamanda sanat ve estetik değerleri, sosyal, ekonomik ve siyasi yaşamı hakkında da fikir sahibi olunmasını sağlar. $\mathrm{Bu}$ mimari kalıntıları yerinde görüp, tanımak isteyen turistler, yapıların tarihi, mitolojik hikayeleri, mimari özellikleri hakkında bilgi edinmek veya daha önce edindikleri bilgiler doğrultusunda geçmiş uygarlıklara ait kalıntıları yerinde görmek için seyahatlerde bulunurlar.

Mersin ili coğrafyasının kendisine sunduğu doğal güzelliklerin yanı sıra tarihi ve kültürel dokusuyla da yüksek turizm potansiyeline sahiptir. Eşsiz tarihi ve doğal güzellikleri barındıran kentte birçok antik kent bulunmaktadır. Fakat hak ettikleri değerden maalesef yoksun bırakılmaktadırlar. Bu sorununun temelini ise; tanıtımdaki eksiklikler oluşturmaktadır. $\mathrm{Bu}$ çalışma sonucunda kültür turizmi kavramı ve Olba antik kentinin kültürel açıdan önemi ortaya konulduktan sonra, sunulan öneriler ile tanıtım ve kentin bilinirliliği sorununun çözülmesi hedeflenmiştir.

Her disiplinin diğer bilim dalları ile ilişkisi olduğu gibi turizmin de sanat tarihi ve arkeoloji ile yakından ilişkisi vardır. Mersin ili sınırları içerisinde yer alan Olba antik kenti kazıları hala devam etmekte olup, her yeni kazı sezonunda yeni buluntular elde edilmektedir. Erken Hristiyanlık dönemine ait izler taşıyan bu antik kent birçok dini ve sivil yapısıyla büyük ve sosyal bir kent olma özelliği taşımaktadır. Kültür turizmi kapsamında önemli bir ören yeri olacak olan Olba antik kenti Mersin ilinin de turizm profilini değiştirecektir. Turizm potansiyeli oluşturulması için gerekli tedbirlerin alınması ile Mersin ilinin turizm ekonomisine sağlayacağı katkı da artacaktır.

\section{KÜLTÜR TURİZMİ KAVRAMI}

Etimolojik açıdan incelendiğinde kültür kelimesinin Latincedeki "tarım" anlamına gelen "Cultura" kelimesinden geldiği ve 12. yüzyıldan beri kullanıldığı görülmektedir. "Cultura" sözcüğü kullanılmaya başlandığı ilk dönemlerde tarımsal üretimi, ekip biçmeyi ifade etmede kullanılırken; 19. yüzyıldan itibaren toplumların becerileri, sanatları, gelenekleri ve yaşama biçimini anlatmada kullanılmıştır (Öter ve Özdoğan, 2005:127).

Kültür turizmi sözcüğüne ilk kez 1980'li yılların başında Avrupa Komisyonu tarafından Avrupa Birliği'nin kültürel kimliğini ve kültürel mirasını ortaya çıkarmak amacıyla yaptığı çalışmalar sırasında rastlanmışır (Çulha, 2008:1829). 


\section{Fatma ŞENGÜL}

Kültür turizmi yeni kültürleri tanıma, geçmişteki kültürleri merak etme temeline dayanan, insanların kendi kültürlerinin eğlence yanlarıyla birlikte diğer gruplarının kültürüne de açık olan yanlarıyla ilgili turizm faaliyetlerinin tümünü kapsar. Kültürel turizm; insanların kültürel açıdan zengin yöreleri görmek, gittikçe kaybolan yaşam biçimlerini öğrenmek ve izlemek, kültürel değerleri bir anı olarak toplamak amacıyla yaptıkları gezilerle ilgili bir turizm çeşididir (Avcıkurt 2003:10).

Kültür turizmi; insanların sürekli bulundukları yerden geçmiş medeniyetlere ait sosyal, ekonomik, siyasal ve etnik özellikleri hakkında detaylı bilgi sahibi olmak, onlardan geriye kalan kalıntıları yerinde görüp incelemek amacıyla gerçekleştirdikleri ziyaret ve bu ziyaret sırasında satın aldıkları turistik mal ve hizmetler sonucunda oluşan faaliyetlerin tümü olarak tanımlanabilir.

Tarihte Hitit, Urartu, Likya, Lidya, İyon, Roma, Selçuklu, Osmanlı gibi birçok uygarlığa ev sahipliği yapan Türkiye sahip olduğu tarihi taşınır ve taşınmaz kültür varlıklarıyla ve doğal zenginlikleri ile çeşitlilik göstermektedir. Avrupa'daki turizm hareketlerinin çoğunu kültür turizmi ve kültürel eserlere yönelik seyahatler kapsar. Fakat; Türkiye'de turizmin temelini hala deniz kum güneş üçlüsü oluşturmaktadır. Özellikle antik dönem, Selçuklu, Osmanlı eserleri, anıtsal yapılarına yönelik yapılan ziyaretlerde gerek süsleme gerekse mimari planlarından etkilenen turistler ülkeyi daha çok merak edip, farklı destinasyonlarda da benzer özellikleri araştırma yoluna gider. Bu bağlamda kültür turizmi bir ülkenin turizm gelişiminde önemli rol oynar.

Kültür turizmi, kültür sanayileri, yaratıcı sanayiler ile turizm ve seyahat arasında entegrasyon sağlayan tek yoldur. Türkiye turizminde kârlı, sürdürülebilir ve sorumlu olabilecek tek yaklaşım kültür turizmidir (Pekin, 2011:13). Farklı coğrafyalardaki farklı toplumlardan günümüze kalan farklı özellikte kültürel miras eseri bulunmaktadır. Her ne kadar birbirinden farklı özellikte olsalar da, toplumların birbirinde etkileşimi sonucunda ortak karaktere bürünebilmektedirler.

McKercher ve Cros; kültür amaçlı seyahat eden turistleri amaçları bakımından beş gruba ayırmaktadırlar; amaçlı gezenler, çevreyi görmekle yetinenler, kaşifler, kültüre ilgisi zayıf olanlar, rastlantısal ziyaretçiler. Amaçlı ziyarertçiler içlerinde konularına amaçlı ziyaretçiler konularına hakimdirler. Kaşifler ise; katıldı ğı bir kültür gezisi sırasında belli bir kültürel konuya olan ilgisini keşfedip amaçlı ziyaretçi olmaya yönelirler. Çevreyi görmekle yetinenler kültüre meraklıdır ancak bilgileri yetersiz olduğundan kısa ziyaretlerle yetinirler. Kültüre ilgisi zayıf olanlar bu tur gezilere nadiren katılırlar ve fazla ilgilenmeden gezinin bitmesini beklerler. Rastlantısal ziyaretçiler planlamadan bu tür gezilere katılır ve konuyla ilgisi olmadığından ziyareti hemen bitirmeye çalışırlar (Öter ve Özdoğan, 2005:29).

Turistler, kültürel varlıkların potansiyel birer kullanıcılarıdır. Turizm ve kültürel miras arasında önemli bir ilişki bulunmaktadır. Bu nedenle, kültür turizmi, kültür miraslarının korunması ve yönetilmesi süreçlerinde etkili bir rol oynayabilmektedir. Turistlerin de kültürel varlıkları kullanan gruplar olduğu göz önüne alınırsa, turizmin etkin bir şekilde kontrolünün sağlanması gerekmektedir (Mckercher ve Cros, 2002:58-59). Kültür turizminde özellikle ören yerleri ve açık hava müzelerinde turist yoğunluğundan kaynakalanan bilinçli veye bilinçsiz tahribatlar meydana gelmektedir. Sahip olunan mirası turizme sunup, ülke ekonomisine katkı sağlamak amacıyla yapılan çalışmalar ve projeleri bu değerleri korumak adına da uygulamak gerekmektedir. 


\section{OLBA ANTIKK KENTI}

Mersin, coğrafi konumu itibariyle, Akdeniz Bölgesi'nin Çukurova bölümünün batısında Doğu Akdeniz Havzası'nın önemli bir bölümünü kapsamaktadır. Mersin 330 km'lik sahil şeridiyle, Türkiye' nin en uzun sahil şeritlerinden birine sahiptir (Mersin Ticaret ve Sanayi Odası, 2008:90).

Coğrafi konumu ve eski dönemlere kadar uzanan geçmişi ile ilk çă̆'dan bu yana sürekli yerleşim bölgesi olmuştur. Bölgenin bilinen en eski adı, Hititler döneminden kalma Kizzuwatna'dır. Antikçağda Kilikia adını alan bölgeye daha sonra aşılması güç engebelerle dolu olması nedeniyle Dağlık Kilikia (Kilikia Trakheia) denilmiştir (Turizm Bakanlığı, 2002:1270 ).

Olba antik kenti ise; Mersin'in Silifke ilçesine bağlı Örenköy yakınlarındaki Uğuralanı Mahallesi'nde yer almaktadır. Bugün, Mersin İlinin Silifke İlçesi, Uzuncaburç Beldesi "nin doğusunda yer alan Olba Kenti, Hellenistik Dönemden itibaren Dağlık Kilikia'nın doğu kesiminde, Olba territoriumu sınırlarında denizden yaklaşık 1100m yükseklikteki bir akropolis çevresinde gelişmiş bir yerleşim merkezidir. İki vadi arasında yer alan akropolisin kuzeyinde verimli tarımsal alanlar yer almaktadır (Özyıldırım, 2003: 153).

Olba sözcügü̈nün kelime anlamı Antik Yunancada "şanslı", "mutlu", "başarılı" anlamına gelmekte olup, yanlış yazımlardan kaynaklı olduğu düşünülen "Olbe", "Olbi", "Oropus", "Oropa" gibi birçok kullanımı mevcuttur (Özyıldırım, 2003: 154).

Olba antik kenti'nin kültürel varlıkları ile ilgili ilk incelemeler Keil ve Wilhem tarafından 1930'lu yıllarda yaptıkları yayınlarda yerleşim merkezinin topografik planını, anıtların ve mezarlık alanlarının tanımlarını bilim dünyasına sunmasıyla başlamıştır (Erten, 2002: 185).

Olba'daki sistemli araştırma ve kazı çalışmaları Mersin Üniversitesi tarafından başlatılmış olup, daha sonra Gazi Üniversitesi Öğretim Üyesi Prof. Dr. Emel ERTEN başkanlığındaki bilimsel ekip tarafından 2001-2009 yılında yüzey araştırmaları ile devam etmiş, 2010 yılında arkeolojik kazılara başlanmıştır ve her yaz döneminde düzenli olarak devam etmektedir.

“Roma'nın MÖ 1. yüzyılda korsanlara karşı verdiği mücadeleler sonucunda Cilicia'da Roma varlığ1 ve gücü duyumsanmaya başlanır. İlerleyen süreç içinde, surla çevrili, Hellenistik Dönem'de kulelerle güçlendirilmiş bir kale yerleşimi olan Olba, Romalı etkilerin bölgeye girmesiyle bir kent kimliği kazanmaya başlar. Olba'nın bağımsız olarak sikke basmasıyla da “kent" niteliği kazandığı söylenebilir "(Özyıldırım, 2003:147).

Arkeolojik veriler sonucunda Olba yerleşim merkezinde yaşanan evreler Helenleşme, Romalılaşma ve Hristiyanlaşma şeklinde ortaya çıkarmış olup, Erken Hristiyanlık Dönemi yazılı belgelerinde ise; psikoposluk merkezi olarak geçmektedir. Zeus'un tahtı veya şimşek betimlerinin yer aldığı M.Ö. 1. yüzyıla tarihlenen kente dair en erken sikkeler ile mimari, seramik, cam ve epigrafik bulgular 1şığında en erken tarihsel bilgilerin Geç Hellenistik ve Erken Roma İmparatorluk Dönemi'ne dayandığı bilinmektedir (Erten ve Özyıldırım, 2008: 53). Eski Yunan'da Olba krallığının merkezi ve ticaret merkezi konumunda olan kentin özellikle Erken Hristiyanlık döneminde yakınında bulunan Diocaseria ile ayrı ayrı piskoposluk merkezi olması Hıristiyan turistler için dini açıdan da ziyaret alanı olarak önem taşıdığını gösterir.

\section{Olba Antik Kenti Kültür Turizmi Çekicilikleri}

Bir antik kentin en önemli özelliği kentsel mimari yapılara sahip olması ve sosyal, dini ve siyasal hayata dair izler taşımasıdır. Bu izler kente karşı ilgiyi ve çekiciliği arttıran unsurlardır. Antik çağlar süresince kentler, sosyal, siyasal ve ekonomik yaşamın merkezi olmuştur. Dolayısıyla, bu 


\section{Fatma ŞENGÜL}

işlevleri karşılayacak yapılara ihtiyaç duyulmuştur. Olba antik kenti bu özelliklerin hepsini barındırarak sistemli bir kent olma özelliğine sahiptir.

Olba Antik Kenti'nin çekicilikleri arasında, Anıtsal Çeşme Yapısı (Nymphaeum), Tiyatro, Nekropol Alanı, Tapınak Mezar, Su Kemeri (Aquaeductus ), Manastır ve Katedral yer almaktadır.

Olba'nın en görkemli anıtları, Roma İmparatorluk Dönemi'ne aittir. Septimus Severus zamanında yapılmış olan Anıtsal ÇeşmeBinası(Nymphaeum) ve Su Kemeri (Aquaeductus) ziyaret edilecek temel anıtlardır. Su kemeri, nekropolün (mezarlık alanı)'nın bulunduğu vadi üzerinde kuruludur ve Limonlu Irmağı üzerindeki Kızılgeçit kaynağından taşınan su Olba'ya bu sistem sayesinde ulaşır. Su kemerinin üzerindeki Yunanca yazıt döneme ait bilgiler vermektedir. Yazıtta su kemerinin Septimus Severusa adanmış olduğu anlaşılmaktadır. Su kemeri bir kentin su ihtiyacını karşılamak için tamamen kayaya oyularak oluşturulan büyük bir sarnıca hizmet etmiştir. Aynı zamanda su kemeri aracılığıyla da vadiyi aşarak, kentin kuzeybatısında bulunan anıtsal çeşme binasına ulaşır (Erten, 2002:186)

Olba'da arkeolojik kazılarla ortaya çıkarılan başlıca anıt, tiyatrodur ve yapı, Roma yönetimi altında kentin kültürel ve sosyal açıdan gelişmişliğinin göstergesidir. Bir bölümü ayakta olan tiyatro çeşmenin yanında yer almaktadır. Tiyatro binasının bazı oturma basamakları ile sahnesinin bir bölümü günümüze dek kalmıştır.

Olba'da yerleşim alanının her köşesinde çok sayıda ve çeşitlilikte mezarlıklar yer alır. Kaya mezar, lahit ve tapınak planlı anıtsal mezar tipi olmak üzere üç mezar tipi görülür. Olba'daki kaya mezar mimarlığının en güzel örnekleri arasında vadi tabanından yaklaşık $9 \mathrm{~mm}$ yükseklikteki mezarın kemerli cephe düzenlemesi vardır. Birbirine açılan üç farklı mekandan oluşan yapı bir mezarlık kompeksi niteliğindedir (Erten, 2003:107)

Şeytanderesi Vadisi'nde yer alan manastır ise, Olba"daki Erken Hıristiyanlık Dönemi açısından en önemli dinsel yapıdır . İmparator Zeno "nun tahta geçişiyle bölgede başlayan parlak dönemin ve hızlanan yapım etkinliğinin bir ürünü olarak 5.yüzyılın ikinci yarısı içinde inşa edilmiştir (Yavuz, 2015:15). Şeytanderesi Vadisi içinde yaklaşık $3 \mathrm{~km}$. güneyde yer alır. Mağara - Kilise, yaklaşık III. yüzyıla tarihlenmektedir ve Olba kentinde Hıristiyanlığın en erken dinsel mekânı olması bakımından son derece önemlidir. Mağara'nın Hıristiyanlık öncesinde de kullanımı olabileceği, üzerinde düşünülmesi gereken bir olgudur. Mağara - Kilise, hemen mağaraya girişin doğu yönüne doğru 5. yüzyılda yapılan kilise kalıntısıyla da önemini sürdürdügünü göstermektedir (Özyıldırım, 2012:215).

2015 yılı kazılarında Olba Antik Kenti'nde üç portreden ve pelerinli melekten oluşan, 1800 yıllık bir mozaik bulunmuştur. Silifke Müze Müdürlügü bahçesine kaldırılan mozaik, iki farklı panodan oluşuyor. Mozaik panolarından birinde, geometrik süslemeler arasında birer kadın ve ortada bir erkek olmak üzere toplam üç portre yer almaktadır. Tryphe, Bios ve Lucia olduğu düşünülen mozaiklerin lüks yaşamı sembolize ettiğine yönelik görüşler vardır.

\section{SONUÇ VE ÖNERİLER}

Dünyada deniz-kum-güneş turizmi stratejisinden kültür turizmine yönelim hız kazanmaktadır. Birçok uygarlığa ev sahipliği yapan Türkiye sahip olduğu tarihi ve kültürel mirasıyla dünyadaki birçok ülkeden daha fazla turizm potansiyeline sahiptir. Fakat, kültür turizmini göz ardı etmekte ve dünya kültür turizmi pazarından istenilen payı alamamaktadır. Türkiye, tarihi ve kültürel güzelliklerini sahip olduğu doğal güzellikler ile harmanlayarak sunduğu taktirde kültür turizminde başarıyı yakalaması kaçınılmazdır. 
Mimari kalıntılar bir ülkenin sahip olduğu köklü tarih hakkında bilgi verirken; aynı zamanda sanat ve estetik değerleri, sosyal, ekonomik ve siyasi yaşam hakkında da bilgiler verir. Bu mimari kalıntıları yerinde görüp, tanımak isteyen turistler, yapıların tarihi, mitolojik hikayeleri, mimari özellikleri hakkında bilgi edinmek veya daha önce edindikleri bilgiler doğrultusunda geçmiş uygarlıklara ait kalıntıları yerinde görmek için seyahatlerde bulunurlar. Anadolu topraklarında doğu'dan batıya kadar birçok uygarlığa ev sahipliği yapmış antik kent yerleşimi mevcuttur.

Mersin ili; ören yerleri, doğası, ve tarihi merkezleri ile kültür turizmi açısından önemli şehirler arasında yer almaktadır. Mersin il sınırlarında bulunan Olba antik kenti de kültür turizmi açısından cazip bir destinasyon alanı olmaya adaydır. Erken Hristiyanlık dönemine ait izler taşıyan bu antik kent birçok dini ve sivil yapısıyla büyük bir kent olma özelliği taşımaktadır. Bu antik kentin önemi son yıllarda yapılan kazı çalışmaları ile daha çok ortaya çıkmıştır.

Su Kemeri (Aquaeductus), Anıtsal Çeşme Yapısı (Nymphaeum), Tiyatro, Nekropol (mezar) alanı, Tapınak Mezar, Manastır ve Katedral Olba kentinde ziyaret edilebilecek başlıca anıtsal yapılar arasındadır.

2015 yılı kazı döneminde çıkarılmış olan Tryphe, Bios ve Lucia taban mozaikleri'nin Mersin müzesinde yer alacak olması müze ziyaretinin de çekiciliğini arttıracaktır. Sanatsal değeri olan bu eserlerin tanıtılması bölgenin çekiciliğini arttırmada önem teşkil eder. Nitekim; Gaziantep'in turizm simgesi haline gelmiş olan Çingene Kızı Mozaiği gibi Olba mozaikleri de Mersin'in yeni çehresi olması yadırganamaz.

Mersin Türkiye'de önemli bir turizm destinasyonu olmasına rağmen, yüksek turizm hareketliliğine ve turist sayısına ulaşamamış, elde edilen turizm gelirinin Türkiye ekonomisi içerisinde payı düşük kalmıştır (Duman ve Öztürk 2005:9). Bu ilin bir parçası olmasına rağmen Olba antik kenti de kültürel değerlerine karşılık turizm pazarı yaratılamamaktadır. Bu durumun başlıca gereken önemin verilmemesi, yanlış turizm stratejisi ve plansızlık gibi sebeplerdir. Kentin, kültür turizminde istenilen payı alabilmesi için aşağıdaki önerilerin dikkate alınması faydalı olacaktır:

- Yerel yöneticilere büyük görevler düşmektedir. Yerel yönetim tarafından gerekli tanıtım faaliyetleri uygulanmalıdır.

- Yerel yönetim tarafından talep edilecek hükümet destekleri ve teşvikler ile Olba antik kentinin çevre ve ulaşım düzenlemesi yapılarak ziyaret edilebilirliliği arttırılmalıdır.

- Özellikle iç turizmde halkın teşvik edilip, iç turizme özendirilmesi, yöre halkına turizm bilincinin oluşturulması için ilgili kamu ve özel sektör kuruluşları birlikte hareket ederek, gerekli çalışmalar yapılmalıdır.

- Sivil toplum kuruluşları, turizm işletmesi yöneticileri, turizm akademisyenleri ve çalışanları ortak çalışmalar ve projeler geliştirerek, hayata geçirmelidir.

- Şüphesiz paket turlarda erken rezervasyon fırsatları yerli ve yabancı turistlere ilgi çekici gelmektedir. Bölge bazında erken rezervasyon politikasının geliştirilip, istikrarlı bir şekilde uygulanması fayda sağlayacaktır.

- Günümüzde teknoloji hızla ilerlemekte, ve insanlar sosyal medya vasıtası ile sık iletişim kurmaktadır. Dolayısıyla, teknolojinin sunmuş olduğu bu güç kullanılmalı, internet ve sanal reklamlarla arkeoloji, sanat ve tarih severlere bu yolla tanıtım yapılmalıdır.

- Bölgede düzenlenen sanatsal etkinlikler, yarışmalar, sergilerde antik kent konu edilmeli, bölgesel, ulusal, uluslararası düzeyde gerçekleştirilen resim, fotoğraf yarışmalarında tema olarak seçenekler arasında yer almalıdır.

- Bölgede ve tüm hediyelik eşya satış noktalarında kentin değerlerini ortaya koyan biblo, anahtarlık, magnet v.b. gibi küçük hediyelik eşyalar ile tanıtım yapılmalı, antik kenti cazip hale getirecek bir logo resim belirlenmelidir. Bu logonun son dönemde ortaya çıkan 


\section{Fatma ŞENGÜL}

mozikler olması ileŞehir üniversitelerinde yapılan kongre, sempozyumlarda bölgenin tanıtımına katkı sağlayacak çalışmalara yer verilmelidir.

- Ulusal ve uluslar arası fuarlara katılım sağlanarak şehrin tanıtımı içerisinde Olba antik kentine de yer verilmelidir.

- Olba'nın tarihi ve kültürel özelliklerini ortaya çıkaran el kitapçıkları, broşürler Türsaba bağlı seyahat acentalarında bulundurulup, turistik ürün olarak sunulmalıdır.

- Tur operatörü ve seyahat acentalarının düzenlemiş oldukları tur programı içerisine bu antik kenti de rotalarına eklemeleri en büyük faydayı sağlayacaktır.

- TUREB, TURSAB ve yerel yönetimin desteğiyle ortak bir çalışma yaparak öncelikle turist rehberleri olmak üzere, turizm çalışanlarına yönelik tanıtım turu düzenlemesi sektör çalışanlarının bölgeye hakim olmasını kolaylaştıracaktır.

Bölgenin tanıtımını en iyi yapacak olan turist rehberleridir. Mersin bölgesine düzenlenen turlar içerisinde anlatımlarında Olba antik kentine de yer verilmeli, tarihi ve kültürel önemi üzerinde durularak üst düzeyde bilgi sunulmalıdır.

Öneriler doğrultusunda gerekli, önem verildiği taktirde Olba antik kenti turizm pazarındaki rekabet ortamında yerini alacaktır ve ören yeri vasitasıyla bölgeyi ziyaret eden turistlerin bıraktiğı döviz ile bölge ve ülke ekonomisine katkı sağlayacak olup, alternatif turizm çeşidi olarak kültürel amaçla yapılan ziyaretlerin tercih edilen merkezleri arasında yerini alacaktır.

\section{KAYNAKLAR}

Avcıkurt, C. (2003). Turizm Sosyolojisi. Ankara : Turist-Yerel Halk Etkileşimi, Detay Yayınları.

Akçay, Tuna, Bir Arkeolog ve Fotoğrafçı Gözüyle Arkeolojik Alanlarının Fotoğraflanması : Olba Antik Kenti, Ankara.

Çımat, A, ve Bahar, O. (2003). Turizm Sektörünün Türkiye Ekonomisi İçindeki Yeri ve Önemi Üzerine Bir Değerlendirme. Akdeniz Üniversitesi İ.I.B.F. Dergisi, 6 (3):1-18.

Çulha, O. (2008). "Kültür Turizmi Kapsamında Destekleyici Turistik Ürün Olarak Deve Güreşi Festivalleri Üzerine Bir Alan Çalışması", Journal of Yasar University, 12(3):1827-1852

Değirmencioğlu, A. Ö. ve Ahipaşaoğlu, S. (2008). Anadolu'da Turizm Rehberliği Temel Bilgileri. Ankara: Gazi Kitabevi.

Duman, T. ve Öztürk, A. B. (2005), "Yerli Turistlerin Mersin Kızkalesi Destinasyonu ve Tekrar Ziyaret Niyetleri ile İlgili Algılamaları Üzerine Bir Araştırma", Anatolia: Turizm Araştırmaları Dergisi, 16(1):9-23

Erten, E. (2002). Mersin Silifke Olba Yüzey Araştırması Sonuçları Toplantısı, Anmed, 185.

Erten, E. (2004), Mersin Silifke Olba Yüzey Araştırması 2003, Anmed.

Erten, E. ve Özyıldırım, M. (2008). Mersin Silifke Olba Yüzey Araştırması 2006. XXV. Araştırma Sonuçları Toplantısı, 2(25):53-54.

McKercher, B. and Cros, H. (2002). Cultural Tourism, The Partnership Between Tourism And Cultural Heritage Management. New York: The Hawort Pres.

Mersin Ticaret ve Sanayi Odası. (2009), 2008 Ekonomik Rapor, Mersin: Başak Ofset.

Özyıldırım, M. (2003). İlkçağ ve Erken Hıristiyanlık Kaynaklarında Olba Sözcüğünün Değişik Kullanımları. Olba, (VIII), 147- 148. 
Türk Turizm Araştırmaları Dergisi

Öter, Z. ve Özdoğan, O. (2005). Anatolia: Turizm Araştırmaları Dergisi, 16 (2).

Pekin, F. (2011). Çözüm: Kültür Turizmi, Turizm ve Kültür Politikaları, İletişim.

Turizm Bakanlığı. (2002). Türkiye'nin Turizm Değerleri 3, Ankara: T.C. Turizm Bakanlığı Tanıtma Genel Müdürlüğü Yayınları.

Usal, A. ve Kuşluvan, Z. (1998). Davranı̧̧ Bilimleri. İzmir: Barış Yayın.

Yeğin, Y. (2015). Olba Manastırı Kazıları - Mimari Buluntuları ve Mekan İlişkileri, Gazi Üniversitesi Sosyal Bilimler Ana Bilim Dalı, Ankara. 